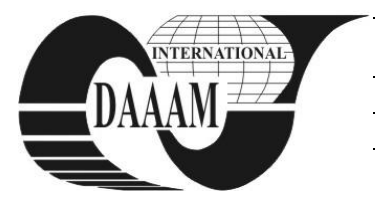

Annals of DAAAM for 2012 \& Proceedings of the 23rd International DAAAM Symposium, Volume 23, No.1, ISSN 2304-1382 ISBN 978-3-901509-91-9, CDROM version, Ed. B. Katalinic, Published by DAAAM International, Vienna, Austria, EU, 2012 Make Harmony between Technology and Nature, and Your Mind will Fly Free as a Bird

\title{
AUTOMATIC PALLET CHANGER MECHANISM USED ON MACHINING CENTERS
}

\author{
MIHAILA, L[ucian]; FUNARU, M[arian]; OBREA, C[laudiu] F[lorin] \& ANDRIOAIA, D[ragos]
}

\begin{abstract}
With a view of shortening the auxiliary times regarding tool and workpiece changing, conventional machine tools are equipped with automatic tool changers and automatic pallet changers, thus becoming machining centers. Reducing the time consumed with the change of the workpiece to follow in machining implies the existence of another table - i.e. the pallet - on which the workpiece is positioned and clamped, while on the working area of the machine another part is manufactured. This paper is presenting a new automatic pallet changer mechanism which is hydraulically driven, along with its guiding and transmission systems.

Key words: Machining center, Pallet, Automatic Pallet Changer, Workpiece
\end{abstract}

\section{INTRODUCTION}

With the widely automation of manufacturing processes in metal cutting industry, the use of machining centers has become increasingly dense. The numerical control allows a variety of operations and settings to be structured in continuous cycles, making machining centers adaptable to both small series and medium to large series production.

Customer satisfaction, a process flow with minimum setup times for tools and workpieces are very important issues that machine tool manufacturers must take consideration of [1]. For this purposes machining centers are equipped with a tool magazine, an automatic tool changing mechanism and a palletizing system. The advantages of machining centers are especially emphasized for parts that require complex and large numbers of machining operations. In the context to achieving these advantages it is necessary to cover some technical and organizational steps to eliminating downtime due to technical problems that might occur to the machine tool, an important role is played by the pallet and the palletizing system [2]. By reducing the secondary processing time in workpiece handling (that is the time consumed with the pallet change) the productivity is highly increased through the ability of the changing devices to simultaneous load and unload along with storing workpieces/pallets.

The palletizing system consists of two mechanisms: the automatic pallet changer and the clamp/unclamp mechanism which is situated on the machining center table. The pallet positioning and clamp/unclamp mechanism secures (clamps) and releases (unclamps) the pallet on the machine tool table (positioning base), such a mechanism is presented in [3]. The pallet changing mechanism is a device which role is to change the pallets carrying the workpieces from the pallet loading station/pallet magazine to the machining center table/workstation. The main advantage of pallets is that they can be used for both transport and storage of workpieces.

In designing pallet changing mechanisms the following aspects must be considered: precise indexing of the workpiece; assuring the relative position between the workpiece and the tool on each pallet; easy removal of chips from the workpiece and machine table; a rigid structure.

A classification of pallet changer mechanisms can be issued from the type of movements the mechanism makes in order to change the pallets, so we can assume that there are the following pallet changer mechanisms: linear shuttle pallet changer mechanisms; rotary shuttle pallet changer mechanisms; combined pallet mechanisms.

Linear shuttle pallet changers are using different combinations between drives and transmissions in order to change the pallets. Usually, automatic pallet changers are provided with two stations [4], [5], one having the purpose to load the machining center and the other to store the pallet with the workpiece to follow the process. The driving of these linear shuttle pallet changers can be made hydraulically (linear hydraulic cylinders), pneumatically (pneumatic cylinders) or mechanically (by making use of an electric motor and chain or ball screw transmission).

Concerning the rotary shuttle pallet changers, these are provided with two diametral opposite arms to carry through, like the linear shuttle pallet changers, with the loading and depositing operations. These type of automatic pallet changers are driven electrically in combination with cam transmission [6] or hydraulically and pneumatically, usually with pinion-rack transmission [7].

In the case of both linear shuttle and rotary shuttle pallet mechanisms an important role is played by the machine tool table which slides from one post of the mechanism to the other in order to receive and hand over the pallet. 
The combined pallet mechanisms no longer make use of the machine tool table as they complete all the pallet change operations. Such a mechanisms is widely presented in [2]. Other devices for tool and workpiece changing are presented in [8].

In this paper a novel rotary shuttle mechanism is presented. Its main constructive characteristic is that the mechanism reduces the drive system, transmission and guiding to an double hydraulic piston. The design and functioning are presented in the following sections.

\section{PRESENTATION OF THE DESIGN}

The automatic pallet changer mechanism is rotated using a hydraulic cylinder to automatically exchange the pallet in the machining chamber with the pallet on the loading station. The main components of the automatic pallet changer are shown in fig. 1 as follows: automatic pallet changer arm 1, cam follower 2, positioning pins 3 , safety catch pins 4 , cam 5 , piston 6 (automatic pallet changer arm clockwise and counterclockwise rotation), piston 7 (automatic pallet changer arm up/down), the automatic pallet changer's housing 8 .

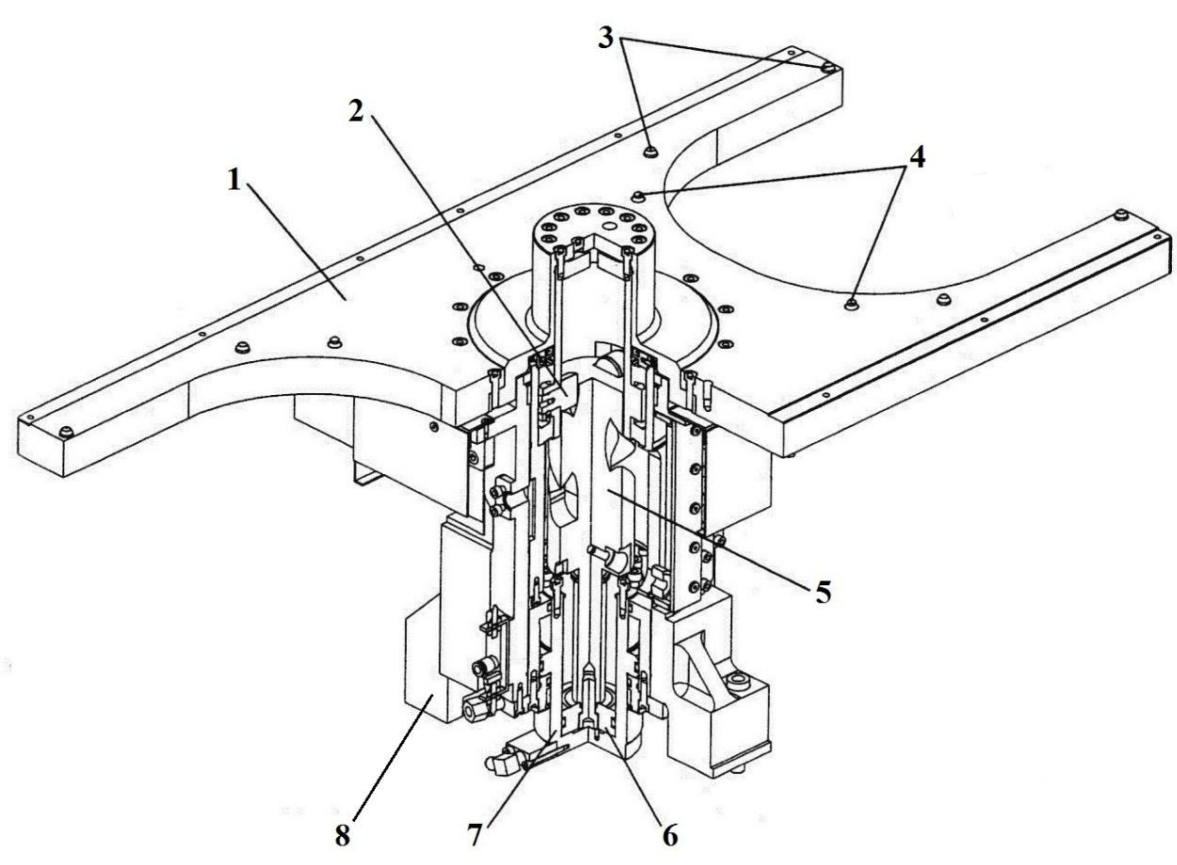

Fig. 1. Automatic Pallet Changer Mechanism

The automatic pallet changer arm 1 is suitable for handling pallets with nominal dimensions up to $800 \mathrm{~mm}$. The pallet is positioned on the automatic pallet changer arm with the help of the positioning pins 3 and the safety catch pins 4 . Any type of pallet which characteristics are the same with the ones mentioned before can be handled by the presented mechanism with the condition that on the lower side of the pallet should be tapered holes to match the positioning pins 3 and the safety pins 4 (fig.1). Through its construction the automatic pallet changer mechanism is capable of performing two main movements: a translation for lifting and lowering the pallet from/to the machining center table and loading station, a rotation for exchanging the pallet from the machining center table with the one on the pallet loading station. Lifting and lowering operations of the automatic pallet changer's arm are made by the hydraulic piston 7 which, once pressure actuated, also lifts or lowers the hydraulic piston 6 . The rotation movement is driven by the hydraulic piston 6 which moves the cam 5 , that engages with the cam follower 2, upward or downward making the automatic pallet changer arm 1 rotate with an angle of $180^{\circ}$ clockwise/counterclockwise.

The automatic pallet changer mechanism can be mounted on the machining center bed through its housing 8 . The mechanism is supplied with hydraulic oil from the machining center's main hydraulic unit.

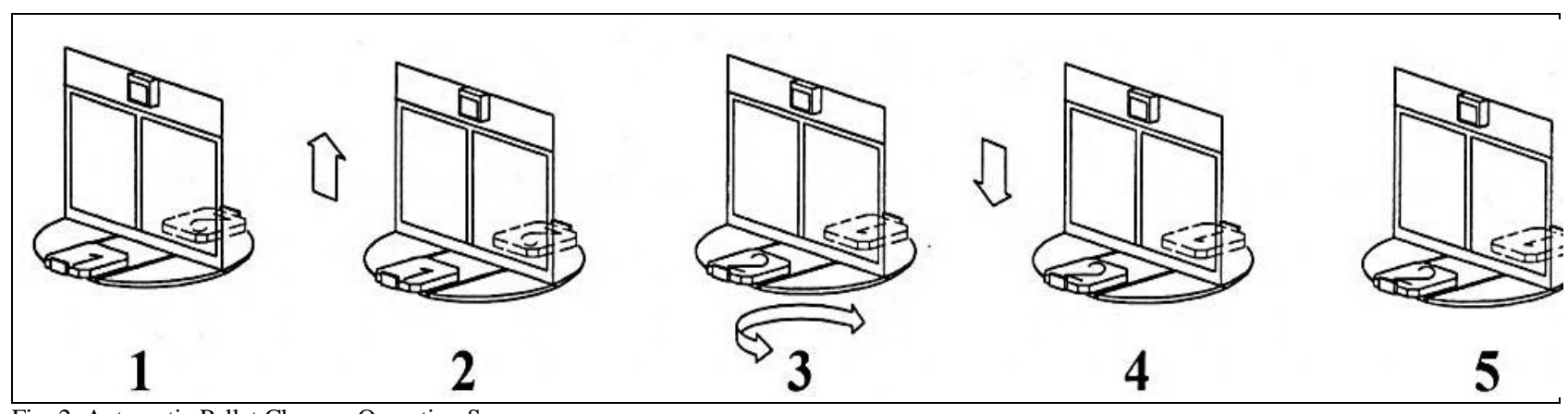

Fig. 2. Automatic Pallet Changer Operation Sequence 


\section{FUNCTIONING}

The automatic pallet change operations take place following the sequence presented in fig. 2 . In the first operation the machining center's table brings the pallet 2 over the pallet changer's arm and performs the unclamp and cleaning (the lower side of the pallet) operation. The following operation consists in lifting the automatic pallet changer's arm along with the pallet 1 from the loading station and the pallet 2 from the machine table. The third operation performs the pallet exchange, moving the pallet from the machining center's table to the loading station and the pallet from the loading station to the machining center's table. The fourth operation consists in lowering the exchanged pallets on the machine table, respectively on the loading station and the fifth operation is the pallet clamp on the machine table.

For the automatic pallet change operation to take start the following conditions must be satisfied: the pallet in the machining chamber must be clamped; the automatic pallet changer arm must be in clockwise or counter clockwise rotation completed status; automatic pallet changer arm is in down position; table in the machining chamber must be clamped; machine table must be in reference position. Summed, the times of completing each sequence (the time consumed with pallet unclamp from the machine table; the time consumed with moving upward the automatic pallet changer's arm; the time consumed with the automatic toll changer's arm rotation with $180^{\circ}$; the time consumed with lowering the pallet changer's arm; the time consumed with the exchanged pallet clamp on the machine table) give the total time of the pallet change. Next we will present the mechanisms for performing the operations mentioned above.

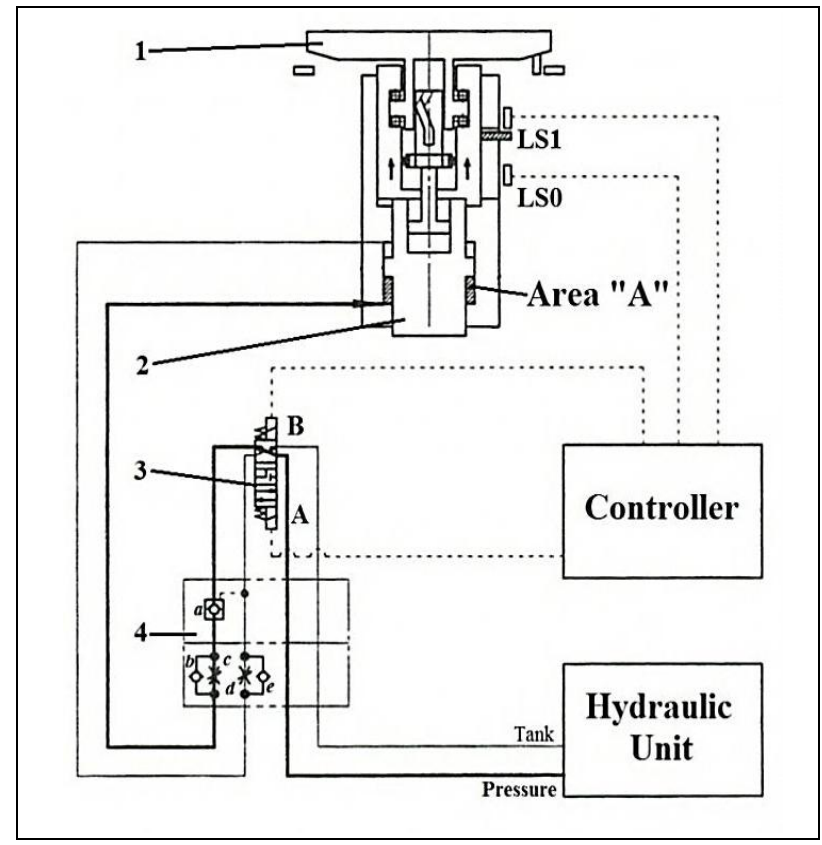

Fig. 3. Automatic Pallet Changer Arm Up Mechanism

\subsection{Arm up operation mechanism}

Fig. 3 presents the drive scheme for the arm up operation mechanism. When the automatic pallet changer arm 1 up is commanded the solenoid valve is energized and changes its position from A (arm down ) to B (arm up) allowing the hydraulic oil to enter area "A". At this moment, under hydraulic pressure the piston 2 is moved upward and the limit switch LS0 switches its position from 1 to 0 . The positioning pins 3 (fig. 3) on the automatic pallet changer's arm 1 engage the tapered holes in the lower side of the pallet so that the pallet is positioned on the arm (pallet is detached from the table). The automatic pallet changer arm up operation is completed when the limit switch LS1 changes its position from 0 to 1 , thus confirming the finality of the operation to the machine controller. The check valvethrottle kit 4 it consists of two subassemblies check valve $(b, e)-$ throttle $(c, d)$ and a hydraulic driven valve $a$. The hydraulic pressure access to area " $\mathrm{A}$ " is made through the hydraulic driven valve $a$ and the check valve $b$. For a clean, shock free upward movement of the automatic pallet changer arm the runback of hydraulic oil is made through the throttle $d$, which has the role to decelerate.

\subsection{Arm down operation mechanism}

Fig. 4 shows the arm down operation mechanism. When automatic pallet changer arm down is commanded the solenoid valve 3 is energized and changes its position from B to A allowing hydraulic pressure to enter area "B". Piston 2 is moved downward by hydraulic pressure, the limit switch LS1 changes its position from 1 to 0 ; automatic pallet changer arm is lowered and the pallet is placed on the table (pallet loading station). The automatic pallet changer arm down operation is completed when the limit switch LSO switches from 0 to 1 and the machine controller confirms completion of the operation. The hydraulic oil is sent to area " $\mathrm{B}$ " through the check valve $e$ from the check valve-throttle kit 4; the hydraulic oil from area " $A$ " is sent to the hydraulic unit's tank trough the throttle $c$ and the hydraulic driven valve $a$, which is unlocked by the pressure from the " $\mathrm{B}$ " area access pipe.

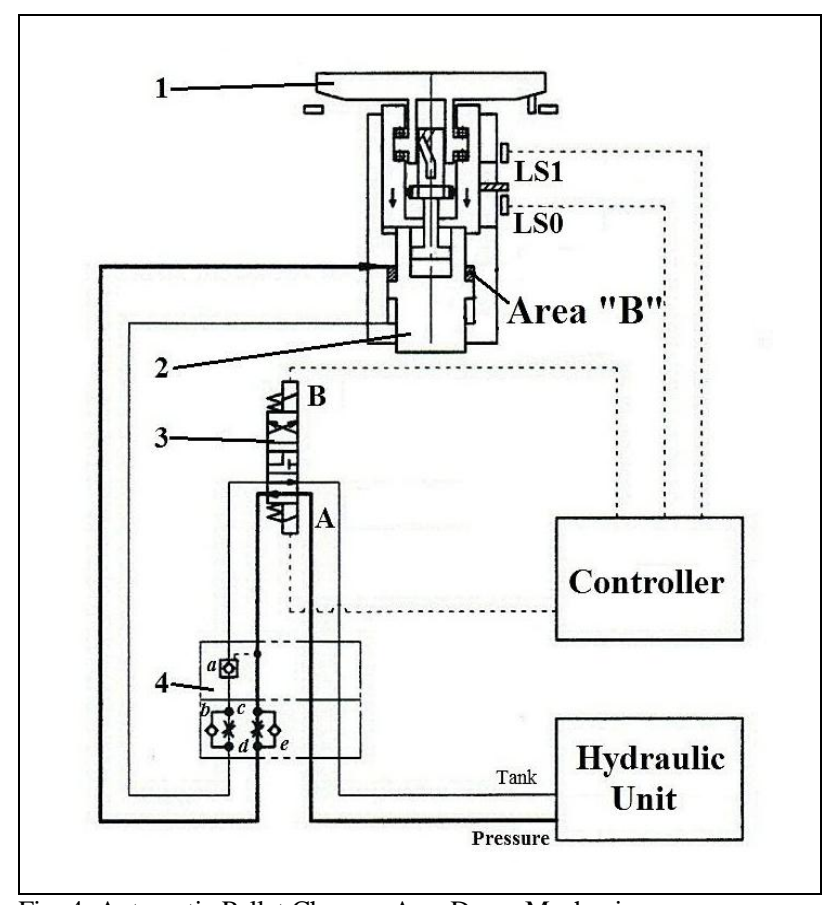

Fig. 4. Automatic Pallet Changer Arm Down Mechanism 


\subsection{Arm clockwise rotation operation mechanism}

The automatic pallet changer arm rotates with $180^{\circ}$ when exchanging the pallets on the table and the pallet loading station. The arm rotation operation is also performed hydraulically. The drive scheme for the automatic pallet change clockwise rotation mechanism is shown in fig. 5. When automatic pallet change arm rotation is commanded the solenoid valve 3 changes its position to A allowing hydraulic oil to enter area "B"; the piston 2 moves downward and the cam 2 moves downward; the automatic pallet changer arm is rotated $180^{\circ}$ clockwise by the $180^{\circ}$ rotation clockwise of the cam follower 2 (fig.1). The limit switch LS3 changes its position from 0 to 1 and the machine controller confirms completion of automatic pallet changer arm clockwise rotation.

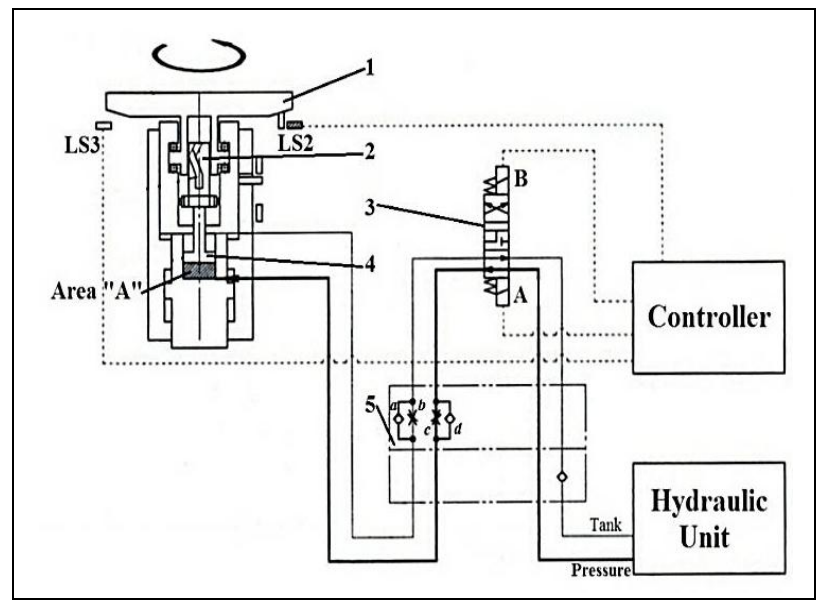

Fig. 5. Automatic Pallet Changer Arm Clockwise Rotation Mechanism

Hydraulic oil access in area " $\mathrm{B}$ " is made through the check valve $a$ from the check valve-throttle kit 5 . For a smooth deceleration of the automatic pallet changer's arm, the runback of hydraulic oil is made through the throttle $c$.

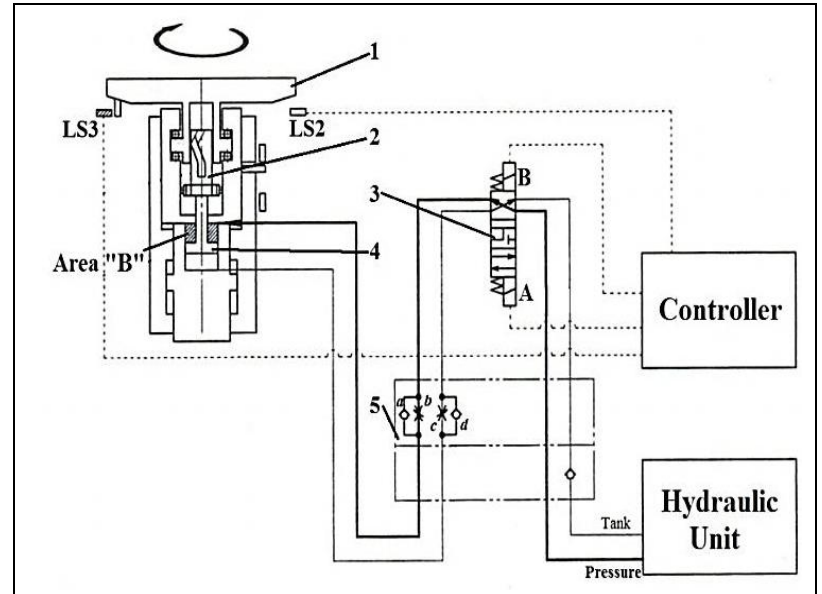

Fig. 6. Automatic Pallet Changer Arm Counterclockwise Rotation Mechanism

\subsection{Arm counterclockwise rotation operation mechanism}

The drive scheme of the automatic pallet changer's arm counterclockwise rotation mechanism is presented in fig. 6. When the automatic pallet changer's arm counterclockwise rotation is commanded the solenoid valve 3 is energized and moves switches its position from $\mathrm{B}$ to A to permit hydraulic oil to enter area "A". Cylinder piston 4 moves upward and the cam 2 moves upward. The automatic pallet changer's arm rotates $180^{\circ}$ counterclockwise due to the $180^{\circ}$ counterclockwise rotation of the cam follower 2 (fig.1). When the rotation of the automatic pallet changer's arm is completed the limit switch LS2 changes its position from 0 to 1 which confirms to the machine controller the completion of arm counterclockwise rotation. Pressure access to area " $\mathrm{A}$ " is made through the check valve $d$ from the check valvethrottle kit 5. The runback of hydraulic oil, like in the case of clockwise rotation mechanism, is also made through a throttle (c), thus assuring a shock free deceleration of the automatic pallet changer's arm.

\section{CONCLUSION}

The automatic pallet changer mechanism presented in this paper can be attached to almost any conventional machine tool along its travel axis. This mechanism is hydraulically driven, being supplied from the machining center's main hydraulic unit, and can be used in handling weights up to $800 \mathrm{~kg}$. The main advantage of an automatic pallet changer is the small setup time of the workpiece to follow in the machining chamber, which is resumed, practically, to the total time take to complete the sequence shown in fig. 2 . Besides this advantage, the automatic pallet changer presented in this paper binds together the drives of the two main movements (up/down translation and clockwise/counterclockwise rotation) into one double hydraulic piston. This solution reduces the space occupied by an extra motor used to perform one of the main movements, and also the manufacturing cost of the automatic pallet changer mechanism is reduced. This mechanism is designed for long live and low maintenance and it's virtually contamination free. As a future development of the automatic pallet changer, it can be integrated in the structure of a pallet magazine, thus, the machining center becomes a flexible manufacturing cell.

\section{REFERENCES}

[1] Daub, C.; Duh, C. (2006). A Model to Enhance the Effectiveness of Machining Centers with Automatic Multi-Pallet Changers: A Case Study, Master Thesis, p. 1, Vajxo University

[2] Stan, Gh. (2003). Pallet mechanism used on machining centers, Buletinul Institutului Politehnic din Iasi , „Gh. Asachi” University of Iasi. Available from: http://www.icms.ro/ icms2k3/papers/2k3008.pdf. Accessed: 2012-04-17

[3] Mihaila, L.; Funaru, M. \& Obreja, C. (2012). PALLET clamp/unclamp mechanism used on machining centre table, Proceedings of ModTech, in press

[4] Midaco Corporation, Full Line Catalog, Available from: http:// www.midacocorp.com /pdfs/HAAS.PPD Accessed: 2012-04-17

[5] User Manual, Sect. 17 - Pallet Changer, (2003), Available from: http://www.fadalcnc.com/Tech_files/UseManuals/ Sect_17_Pallet_Changer.pdf Accessed: 2012-04-17

[6] Pallet Changer CPT, Catalog, Available from: http://www.cdsindexers.com/cnc-machine-tool-products/cpt series.html Accessed: 17.04.2012 Tray Type Automatic Pallet Changer, Available from: http://en.tjr.com.tw/products/ index.php?type_id=52\&top=0 Accessed: $2012-04-17$

[7] Fleischer, J.; Denkena, B.; Winfough, B.; Mori, M. (2006) Workpiece and Tool Handling in Metal Cutting Machines, Annals of the CIRP, Vol. 55 (2), pp.817-938 